\title{
As categorias da alienação e do fetichismo na teoria social marxiana
}

\author{
Jéssica Ribeiro Duboc ${ }^{1}$ \\ https://orcid.org/0000-0003-2390-4902 \\ Maria Lúcia Duriguetto ${ }^{2}$ \\ https://orcid.org/0000-0001-5800-7289 \\ ${ }^{1}$ Universidade Federal do Rio de Janeiro, Escola de Serviço Social, Programa de Pós-Graduação em Serviço Social, Rio de Janeiro, RJ, \\ Brasil \\ ${ }^{2}$ Universidade Federal de Juiz de Fora, Departamento de Fundamentos do Serviço Social, Juiz de Fora, MG, Brasil
}

\section{As categorias da alienação e do fetichismo na teoria social marxiana}

Resumo: O artigo objetiva analisar a teoria marxiana da alienação nos Manuscritos Econômicos-Filosóficos de 1844, Grundrisse e no Livro I d'O Capital. Partimos da premissa que a categoria da alienação adquire novas determinações na teoria social marxiana, que estão organicamente ligadas ao desenvolvimento do modo de produção capitalista e da consequente maturação da crítica da economia política realizada por Marx. Tais determinações se materializam no chamado fetichismo da mercadoria, a manifestação particular da alienação nos moldes da sociabilidade burguesa desenvolvida.

Palavras-chave: Marx. Alienação. Fetichismo.

\section{The categories of alienation and fetishism in Marx's social theory}

Abstract: This article analyzes the Marxian theory of alienation in the Economic-Philosophical Manuscripts of 1844, Grundrisse, and Volume I of Capital. The study assumes that the category of alienation acquires new determinations in Marx's social theory, which are organically connected to the development of the capitalist mode of production and the consequent maturation of Marx's critique of political economy. Such determinations materialize in the so-called "commodity fetishism," the particular manifestation of alienation observed in the developed bourgeois sociability.

Keywords: Marx. Alienation. Fetishism.

Recebido em 01.10.2018. Aprovado em 20.11.2018. Revisado em 16.04.2019.

(C) O(s) Autor(es). 2019 Acesso Aberto Esta obra está licenciada sob os termos da Licença Creative Commons Atribuição-NãoComercial 4.0 Internacional (https://creativecommons.org/licenses/by-nc/4.0/deed.pt_BR), que permite copiar, distribuir e reproduzir em qualquer meio, bem como adaptar, transformar e criar a partir deste material, desde que para fins não comerciais e que você forneça o devido crédito aos autores e a fonte, insira um link para a Licença Creative Commons e indique se mudanças foram feitas. 


\section{Introdução}

O presente artigo $^{1}$ tem por objetivo apresentar um estudo sobre o desenvolvimento da categoria da alienação em Marx contido nos Manuscritos Econômicos-Filosóficos de 1844 (MARX, 2015), nos Grundrisse (MARX, 2011) e no Livro I d'O Capital (MARX, 2013).

Cabe destacar, que o tratamento da teoria da alienação contida nos Manuscritos (MARX, 2015) deve partir dos seus limites históricos e teóricos, uma vez que "o operário que Marx tem em mente é o trabalhador fabril da indústria típica da primeira Revolução Industrial, que duas ou três décadas mais tarde se esgotaria" e que "o movimento revolucionário com o qual Marx se defronta é um movimento emergente, ainda sem expressivas experiências de autonomia". (PAULO NETTO, 2017, p. 170). Não obstante estes condicionantes sócio-históricos e político-organizativos, o central “[...] está em que o Marx de 1844 descobriu (e nunca será demasiado salientar o traço decisivo dessa descoberta) a raiz fundamental e primária do complexo fenomênico da alienação - com a propriedade privada, a divisão do trabalho e a produção mercantil". (PAULO NETTO, 2017, p. 171).

Estas categorias adquirem novas determinações nos constructos teóricos de Marx com o desenvolvimento do modo de produção capitalista (MPC) e da sua crítica da economia política clássica, presentes destacadamente nos Grundrisse (MARX, 2011) - Manuscritos de 1857-58 - e n'O Capital (MARX, 2013). Nosso objetivo consiste em evidenciar o caminho percorrido por Marx até chegar nas formulações acerca do fetichismo da mercadoria - enquanto uma particularidade da alienação no MPC. Consideramos que os Grundrisse (MARX, 2011) apresentam um tratamento da temática da alienação que nos permite compreender a conexão entre os Manuscritos de 1844 (MARX, 2015) e o Livro I d'O Capital (MARX, 2013). Se nos Manuscritos de 1844 "o trabalho alienado refere-se à negação da essência humana, em O Capital tem-se presente a coisificação das relações entre os homens, isto é, descreve-se o caráter fetichista dos objetos (mercadoria, dinheiro e capital) em que tais relações se objetivam ou materializam". (VÁSQUEZ, 2007, p. 433).

Para nós, o resgate da teoria da alienação em Marx, no ano do bicentenário de seu nascimento, é uma condicionante para uma apreensão das suas particulares manifestações nos processos sócio-históricos de desenvolvimento do MPC na contemporaneidade. É nesta direção que Paulo Netto (1981, p. 74) afirma:

\footnotetext{
A alienação, complexo simultaneamente de causalidades e resultantes históricos-sociais, desenvolve-se quando os agentes sociais particulares não conseguem discernir e reconhecer nas formas sociais o conteúdo e o efeito da sua ação e intervenção; assim, aquelas formas e, no limite, a sua própria motivação à ação aparecem-lhes como alheias e estranhas. É possível afirmar (estendendo a investigação para além das sugestões marxianas de 1844) que em toda a sociedade, independentemente da existência de produção mercantil, onde vige a apropriação privada do excedente econômico estão dadas as condições para a emergência da alienação.
}

\section{A categoria da alienação nos Manuscritos de 1844}

São nos Manuscritos de 1844 - obra que refletem a aproximação de Marx com os clássicos da economia política - que Marx, pela primeira vez, "explora sistematicamente as implicações de longo alcance de sua ideia sintetizadora - "alienação do trabalho" - em cada esfera da atividade humana". (MÉSZÁROS, 2016, p. 23). A partir da sua crítica da dialética hegeliana e da economia política, Marx (2015) traz à luz a sua concepção de trabalho alienado, que se diferencia da conceituação de alienação em Hegel tanto quanto à de Feuerbach, ainda que origine delas (KONDER, 2009). No que se refere à diferença da alienação em Hegel, verifica-se que a apreensão hegeliana identifica alienação com objetivação. Para Marx (2015), a objetivação constitutiva do ser social - só se configura como alienação nos marcos das relações de produção capitalista. Em relação à Feuerbach, a alienação refere-se ao homem abstrato e ocorre na esfera da consciência humana. Marx (2015), já nos Manuscritos de 1844, mesmo que com devidas imprecisões, parte dos homens reais, na produção das suas relações sociais.

Para Marx (2015), a objetivação só é alienação em condições históricas determinadas, ou seja, a partir da existência da propriedade privada e das suas conexões com a divisão do trabalho, a produção mercantil e o trabalho assalariado. A objetivação é o trabalho, ou seja, o processo em que por meio do trabalho a força espiritual do homem se corporifica no objeto. O trabalho é para Marx $(2015$, p. 311) a "atividade vital, a própria vida produtiva" e a "vida produtiva é a vida genérica" é a "[...] vida que gera vida"2. O objeto do trabalho é a "objetivação da vida genérica do homem" na medida em que "ele se duplica não só intelectualmente, como na consciência, mas também operativamente, realmente, e contempla-se por isso num mundo criado por ele". (MARX, 2015, p. 311). Assim, "ao considerar o homem como ser prático e social e a práxis como a totalidade 
das objetivações do ser social, construída e constituinte, Marx funda a alternativa para situar a alienação como fenômeno e problema prático-social". (PAULO NETTO, 1981, p. 60). O trabalho é, portanto, o mediador na "[...] relação sujeito-objeto entre homem e natureza [...]” (MÉSZÁROS, 2016, p. 80). Um mediador que permite ao homem conduzir um modo humano de existência, assegurando que ele não recaia de volta na natureza, que não se dissolva no objeto.

É com essa apreensão, que nos Manuscritos (MARX, 2015) a noção de trabalho é conceituada tanto como o seu termo geral, que se refere à atividade produtiva, enquanto determinação ontológica fundamental da humanidade, assim como o seu termo particular no modo de produção do capital, que é o trabalho assalariado, configurando o trabalho que é a base de toda alienação - trabalho alienado (MÉSZÁROS, 2016).

Marx (2015), no Caderno I dos Manuscritos, intitulado Trabalho Alienado e propriedade privada, afirma que a economia política clássica não analisa os fundamentos da propriedade privada, tomando-a como lei eterna, natural e a-histórica. Assinala a necessidade de desocultar a realização do trabalho nas condições da propriedade privada, da divisão do trabalho e da produção mercantil, complexos que fundamentam a explicação do fenômeno da produção da pobreza em paralelo ao da riqueza; da crescente valorização do mundo das mercadorias em detrimento do mundo dos homens e a consequente produção do próprio trabalhador como mercadoria. Neste conjunto de fenômenos, o processo de produção de mercadorias torna o trabalhador alienado do que produz, a realização do trabalho aparece como desrealização do trabalhador, "a objetivação como perda do objeto e servidão ao objeto [...]"(MARX, 2015, p. 304, grifo do autor). O objeto adquire uma existência "[...] independente [...]" e "[...] alienada [...]" ao trabalhador (MARX, 2015, p. 306).

O trabalho alienado, sob a propriedade privada, conformaria determinações fundantes da alienação, quais sejam: "[...] o produto do trabalho não pertence ao trabalhador [...] pertence a um outro homem fora o trabalhador" (MARX, 2015, p. 305), ele já não possui mais nenhum controle sobre a objetivação do seu trabalho, que aparece como desrealização, como frustração. Neste processo, o objeto adquire uma existência exterior ao seu produtor; o trabalhador está alienado dos objetos da produção, uma vez que a alienação também se expressa no interior da atividade produtiva, pois "a energia física e espiritual própria do trabalhador, a sua vida pessoal [...]" aparece como "uma atividade voltada contra ele próprio, independente dele, não lhe pertencendo" (MARX, 2015, p. 310); a alienação da "[...] sua própria função ativa [...]" torna o homem alienado da vida genérica, que é posta como "[...] meio de vida individual”" (MARX, 2015, p. 311); ao alienar-se do produto do seu trabalho, da sua atividade vital e do seu ser genérico, o homem se aliena também do outro homem. Assim, são determinações do trabalho alienado: a alienação do trabalhador em relação ao produto do seu trabalho; a alienação do trabalhador no interior da produção; a alienação do trabalhador do seu ser genérico e, como consequência imediata desta última, a alienação do homem em relação ao outro homem.

Estas determinações da alienação postas nos Manuscritos (MARX, 2015) evidenciam que a propriedade privada é a expressão material, o meio pelo qual o trabalho se aliena, conformando "[...] a relação do trabalhador com o trabalho e com o produto do seu trabalho e com o não trabalhador e a relação do não trabalhador com o trabalhador e o produto do seu trabalho". (MARX, 2015, p. 320). A propriedade privada é, portanto, “[...] a expressão material sensível da vida humana alienada”, e a supressão desta implica na supressão daquela (MARX, 2015, p. 320). Nesta direção, Paulo Netto (2015, p. 75, grifo nosso) observa que:

\begin{abstract}
Com os Manuscritos, o tratamento da alienação experimentou um giro radical: deslocou-se do nível das expressões ideais, anímicas, filosóficas e foi inscrito no mundo prático, efetivo, das relações econômicosociais (e políticas) dos homens. Por isto mesmo, é inerente à - e indescartável da - perspectiva marxiana a ideia de que a superação da alienação não pode nem há de se realizar no domínio da consciência (incluído aí o mais elaborado conhecimento teórico que, evidentemente, é necessário para tal superação): se ela procede por meios práticos, só meios igualmente práticos poderão superá-la.
\end{abstract}

Eis que, a partir dessa passagem, podemos extrair o que Mészáros (2016, p. 13, grifo do autor) denomina de núcleo estruturante do sistema marxiano nos Manuscritos de 1844: a "[...] transcendência positiva da auto-alienação do trabalho [...]", isto é, a superação da propriedade privada, que, de acordo com o autor, é o termo chave para compreender a teoria da alienação. No Caderno III dos Manuscritos, no tópico intitulado Propriedade Privada e Comunismo, Marx (2015, p. 344-345), explicita sua compreensão da superação da alienação: "O comunismo é, por fim, a expressão positiva da propriedade privada superada [...]" na medida em que ela é "[...] a expressão material sensível da vida humana alienada" e a sua superação positiva é a " apropriação da vida humana, isto é, o regresso do homem à sua existência humana e social".

O comunismo, enquanto a supressão positiva da propriedade privada, segundo Paulo Netto (2015), implica em outra forma de produzir, isto é, um novo modo de produção, na medida em que o modo de produção vigente não permite que o homem se realize como tal, pois a propriedade privada aliena o homem de todos os 
seus sentidos físicos e espirituais, como comer, cheirar, saborear, pensar, sentir amar etc., dando lugar a um único sentido, o sentido de ter, uma vez que "a propriedade privada nos fez tão estúpidos e unilaterais que um objeto só é nosso se o tivermos, portanto, se existir para nós como capital, ou se for imediatamente possuído, comido, bebido, trazido no corpo, habitado por nós etc.; em resumo, usado". (MARX, 2015, p. 349, grifo do autor). Portanto, para Marx (2015, p. 350) "a superação [da propriedade privada] é por isso a completa emancipação de todos os sentidos e qualidades humanas [...]".

A teoria da alienação adquire um maior desenvolvimento no decorrer das pesquisas de Marx (2011, 2013) sobre os fundamentos e as determinações do MPC, o que se evidencia nos Grundrisse e n'O Capital.

\section{A expressão particular da alienação no MPC: o fetichismo}

Para Paulo Netto (1981, p. 39), a problemática do fetichismo tem uma importância central na obra marxiana por ser desenvolvida a partir do estudo sobre a mercadoria, a "[...] célula econômica da sociedade burguesa". Uma das questões centrais posta por Marx (2013, p. 147) sobre a mercadoria é de onde provém “[...] o caráter enigmático do produto do trabalho, assim que ele assume a forma-mercadoria?".

Em O Capital, Marx (2013, p. 114) observa que a mercadoria é um objeto externo, uma "[...] coisa [...]" que, por meio das suas propriedades, satisfaz as necessidades humanas independente da natureza dessas necessidades - "[...] se, por exemplo, elas provêm do estômago ou da imaginação [...]" - e pode ser utilizada tanto "[...] como objeto de fruição[...]" ou como meio de produção, retornando ao processo produtivo.

O valor de uso de uma mercadoria é a utilidade que ela carrega no seu conteúdo material, isto é, "[...] o próprio corpo da mercadoria, como ferro, trigo, diamante etc., é um valor de uso ou um bem". (MARX, 2013, p. 114). Sendo assim, o valor de uso é realizado no consumo, na medida em que é utilizado. As propriedades que se expressam no valor de uso representam o conteúdo material da riqueza independente da formação social. Na sociabilidade capitalista, analisada por Marx (2013), o valor de uso constitui, ao mesmo tempo, os suportes materiais do valor de troca.

O valor de troca, a princípio, aparece como uma relação quantitativa. Representa a proporção na qual os valores de uso de um determinado tipo são trocados por valores de uso de um outro tipo qualquer. De acordo com Marx (2013), essa relação se altera constantemente no tempo e no espaço. "Por isso, o valor de troca parece algo acidental e puramente relativo, um valor de troca intrínseco, imanente à mercadoria; portanto, uma contradictio in adjecto [contradição nos próprios termos].” (MARX, 2013, p. 114, grifo do autor).

Quando se observa mais atentamente o valor de troca, percebe-se que as mercadorias para serem trocadas no mercado precisam possuir algo em comum, que as tornam intercambiáveis com qualquer outra mercadoria. Disso Marx (2013, p. 115) extrai as seguintes prévias conclusões: a) “[...] que os valores de troca vigentes da mesma mercadoria expressam algo igual”; b) “[...] que o valor de troca não pode ser mais do que o modo de expressão, a 'forma de manifestação' de um conteúdo que dele pode ser distinguido". O que seria esse algo em comum, sob o qual as mercadorias têm de ser reduzidas para serem intercambiáveis? Para o nosso autor (MARX, 2013, p. 115):

Esse algo em comum não pode ser uma propriedade geométrica, física, química ou qualquer outra propriedade natural das mercadorias. Suas propriedades físicas importam apenas na medida em que conferem utilidade às mercadorias, isto é, fazem delas valores de uso. Por outro lado, parece claro que a abstração dos seus valores de uso é justamente o que caracteriza a relação de troca das mercadorias.

As mercadorias, como valores de uso, são importantes conforme a utilidade que elas carregam nas suas propriedades física e "[...] são, antes de tudo, de diferente qualidade; [e] como valores de troca, podem ser apenas de quantidade diferente, sem conter, portanto, nenhum átomo de valor de uso". (MARX, 2013, p. 116). Ou seja, se retirarmos o valor de uso das mercadorias - as suas propriedades materiais que lhe conferem uma utilidade qualquer - "[...] resta nelas uma única propriedade: a de serem produtos do trabalho". (MARX, 2013, p. 116, grifo nosso). Aqui chegamos a seguinte assertiva: o que torna as mercadorias intercambiáveis entre si, o seu elemento em comum à todas as outras mercadorias é o fato de serem produtos do trabalho humano.

Portanto, se abstrairmos o valor de uso de uma mercadoria, retiramos dela aquilo que lhe confere uma determinada especificidade - o trabalho concreto que foi dispendido em sua produção. O que resta dos produtos do trabalho é apenas "[...] uma mesma objetividade fantasmagórica, uma simples geleia de trabalho humano indiferenciado, i.e., de dispêndio de força de trabalho humana, sem consideração pela forma de seu dispêndio". (MARX, 2013, p. 116). O trabalho abstrato - indiferenciado - significa que no processo de produção da mercadoria foi dispendido força de trabalho humano, que nela "[...] foi acumulado trabalho 
humano", portanto, "como cristais dessa substância social que lhes é comum, elas são valores - valores de mercadorias". (MARX, 2013, p. 116).

Marx (2013) evidencia o elemento comum que possibilita a troca entre as mercadorias ao descobrir que o seu valor é constituído pelo trabalho humano abstrato objetivado na produção das mercadorias. Assim, "o elemento comum, que se apresenta na relação de troca ou valor de troca das mercadorias, é, portanto, seu valor". (MARX, 2013, p. 116). O valor de troca é apenas a expressão, isto é, a manifestação do valor de uma mercadoria. Desta compreensão, surge a seguinte indagação: como pode ser medido esse valor? "Por meio da quantidade de 'substância formadora de valor', isto é, da quantidade de trabalho nele contida." (MARX, 2013, p. 116). Aqui, se desvela a lei do valor da teoria marxiana, qual seja: o valor de uma mercadoria é o tempo de trabalho socialmente necessário para a sua produção.

Como vimos, o valor de troca de uma mercadoria é a expressão ou manifestação do seu valor. Entretanto, aquilo que lhe determina valor, isto é, "[...] o tempo de trabalho socialmente necessário para a produção de um valor de uso [...]" assume a forma "[...] da grandeza de valor dos produtos do trabalho [...]" (MARX, 2013, p. 117). As relações sociais de troca entre os produtores aparecem como uma relação social entre os produtos dos trabalhos, isto é, uma relação entre coisas. Portanto, como valor de uso a mercadoria nada possui de misterioso na medida em que tem por finalidade a satisfação das necessidades humanas, o caráter fantasmagórico se encontra no seu valor de troca, logo ao assumir a forma de mercadoria (MARX, 2013).

Nos Manuscritos preparatórios de 1857/58 - Grundrisse - Marx (2011) demonstra como o valor de troca subverte a relação entre o homem e o seu produto, assim como a relação do homem com os outros homens. Para Marx (2011), em qualquer sociabilidade, o ser é um ser social, que vive e depende mutuamente dos outros homens para a satisfação de suas necessidade, "a dependência recíproca e multilateral dos indivíduos mutuamente indiferentes forma sua conexão social" (MARX, 2011, p. 105), acontece que, mediante o valor de troca, ocorre a subordinação do produto do trabalho e do próprio trabalho à troca, tornando assim, a conexão social entre os indivíduos "[...] um poder social que lhes é estranho, que está acima deles; sua própria interação [aparece] como processo e poder independentes deles". (MARX, 2011, p. 144, grifo do autor). Por essa razão, Marx (2011, p. 105) observa que no MPC "a atividade, qualquer que seja sua forma de manifestação individual e o produto da atividade, qualquer que seja sua qualidade particular, é o valor de troca, i.e., um universal em que toda individualidade, peculiaridade, é negada e apagada". (MARX, 2011, p. 105, grifo do autor, grifo nosso).

A troca, quando mediada pelo valor de troca e pelo dinheiro, pressupõe certamente a dependência multilateral dos produtores entre si, mas ao mesmo tempo o completo isolamento dos seus interesses privados e uma divisão do trabalho social cuja unidade e mútua complementaridade existem como uma relação natural externa aos indivíduos, independente deles. (MARX, 2011, p. 106).

Podemos verificar nos Grundrisse (MARX, 2011) a permanência dos aspectos da alienação ressaltados anteriormente nos Manuscritos (MARX, 2015), entretanto, aqui aparecem relacionados com as múltiplas determinações que compõem a totalidade do MPC. Para o autor (MARX, 2011, p. 106, grifo do autor),

A própria necessidade de primeiro transformar o produto ou a atividade dos indivíduos na forma de valor de troca, no dinheiro, e o fato de que só nessa forma coisal adquirem e comprovam seu poder social, demonstra duas coisas: 1) que os indivíduos produzem tão somente para a sociedade e na sociedade; 2) que sua produção não é imediatamente social, não é o resultado de associação que reparte o trabalho entre si. Os indivíduos estão subsumidos à produção social que existe fora deles como uma fatalidade; mas a produção social não está subsumida aos indivíduos que a utilizam como seu poder comum.

Em O Capital (MARX, 2013, p. 147), na mesma direção, infere que "somente no interior de sua troca os produtos do trabalho adquirem uma objetividade de valor socialmente igual, separada de sua objetividade de uso, sensivelmente distinta" e complementa:

Essa cisão do produto do trabalho em coisa útil e coisa de valor só se realiza na prática quando a troca já conquistou um alcance e uma importância suficientes para que se produzam coisas úteis destinadas à troca e, portanto, o caráter de valor das coisas passou a ser considerado umas com as outras e com os homens. Assim se apresentam, no mundo das mercadorias, os produtos da mão humana. A isso eu chamo de fetichismo, que se cola aos produtos do trabalho tão logo eles são produzidos como mercadorias e que, por isso, é inseparável da produção de mercadorias. (MARX, 2013, p. 147-148, grifo nosso). 
Acima, observamos que no MPC, o objeto - enquanto trabalho privado - reveste-se de um duplo caráter social: por um lado é definido de acordo com a sua utilidade - o seu valor de uso, compondo a totalidade do trabalho social; do outro lado, só satisfaz as necessidades humanas na medida em que pode ser trocada por qualquer outro trabalho privado útil que a ele se equipara - valor de troca. Neste processo de troca, o produtor apreende o caráter duplo do produto do seu trabalho apenas sob o aspecto que lhe apresenta, o seu caráter útil, ou seja, o seu valor de uso. No que se refere ao caráter social do produto - que consiste na igualdade de diferentes trabalhos definida a partir do dispêndio de força de trabalho necessário para a sua produção aparece para o produtor como igualdade de valor entre coisas diversas, dos próprios produtos do trabalho, independente dele, produtor. Portanto,

[...] os homens não relacionam entre si seus produtos do trabalho como valores por considerarem essas coisas meros invólucros materiais de trabalho humano de mesmo tipo. Ao contrário. Porque equiparam entre si seus produtos de diferentes tipos na troca, como valores, eles equiparam entre si seus diferentes trabalhos como trabalho humano. Eles não sabem disso, mas o fazem. Por isso, na testa do valor não está escrito o que ele é. O valor converte, antes, todo produto do trabalho num hieróglifo social. (MARX, 2013, p. 149, grifo nosso).

Diante do produtor, a mercadoria se apresenta como uma objetividade mística que contém em si a capacidade de se autovalorizar (MARX, 2013). Nos Grundrisse, Marx (2011, p. 105) afirma que:

O caráter social da atividade, assim como a forma social do produto e a participação do indivíduo na produção, aparece aqui diante dos indivíduos como algo estranho, como coisa; não como sua conduta recíproca, mas como sua subordinação a relações que existem independentemente deles e que nascem do entrechoque de indivíduos indiferentes entre si. A troca universal de atividades e produtos, que deveio condição vital para todo indivíduo singular, sua conexão recíproca, aparece para eles mesmos, como algo estranho, autônomo, como uma coisa. No valor de troca, a conexão social entre as pessoas é transformada em um comportamento social das coisas; o poder pessoal, em poder coisificado.

Da mesma forma, em O Capital (MARX, 2013), o processo de mistificação do mundo das mercadorias é decorrente do caráter social do trabalho que produz mercadorias, uma vez que os objetos úteis, com os seus determinados valores de uso - que satisfazem as necessidades humanas - se tornam mercadorias porque são produtos de trabalhos privados, independentes. O conjunto desses trabalhos privados conformam a totalidade do trabalho social. Nas palavras de Marx (2013, p. 148): "Como os produtores só travam contato social mediante a troca de seus produtos do trabalho, os caracteres especificamente sociais de seus trabalhos privados aparecem apenas no âmbito dessa troca". Para eles "[...] as relações sociais entre seus trabalhos privados aparecem como aquilo que elas são [...]" (MARX, 2013, p. 148, grifo nosso), isto é, não como relações diretamente sociais entre pessoas em seus próprios trabalhos, mas como relações reificadas entre pessoas e relações sociais entre coisas.

Destarte, a mercadoria é misteriosa pois oculta a essência dos produtos do trabalho humano. As características sociais dos produtos aparecem enquanto característica materiais inerentes a eles. Na medida em que encobre a relação social entre os trabalhos individuais dos produtores e o trabalho total, essa relação social existente se apresenta enquanto algo a margem dos produtores. Portanto,

O caráter misterioso da forma-mercadoria consiste, portanto, simplesmente no fato de que ela reflete aos homens os caracteres sociais de seu próprio trabalho como caracteres objetivos dos próprios produtos do trabalho, como propriedades sociais que são naturais a essas coisas e, por isso, reflete também a relação social dos produtores com o trabalho total como uma relação social entre os objetos, existente à margem dos produtores. É por meio desse quiproquó que os produtos do trabalho se tornam mercadorias, coisas sensíveis-suprassensíveis ou sociais. A impressão luminosa de uma coisa sobre o nervo óptico não se apresenta, pois, como um estímulo subjetivo do próprio nervo óptico, mas como forma objetiva de uma coisa que está fora do olho. No ato de ver, porém, a luz de uma coisa, de um objeto externo, é efetivamente lançada sobre outra coisa, o olho. Trata-se de uma relação física entre coisas físicas. Já a forma-mercadoria e a relação de valor dos produtos do trabalho em que ela se representa não tem, ao contrário, absolutamente nada a ver com sua natureza física e com as relações materiais [dinglichen] que dela resultam. É apenas uma relação social determinada entre os próprios homens que aqui assume, para eles, a forma fantasmagórica de uma relação entre coisas. (MARX, 2013, p. 147-148). 
Para o comunista alemão (MARX, 2013, p. 150), a descoberta científica do segredo da mercadoria “[...] elimina dos produtos do trabalho a aparência da determinação meramente contingente das grandezas de valor, mas não elimina em absoluto sua forma reificada". Neste sentido, afirma,

O que é válido apenas para essa forma particular de produção, a produção de mercadorias - isto é, o fato de que o caráter especificamente social dos trabalhos privados, independentes entre si, consiste em sua igualdade como trabalho humano e assume a forma do caráter de valor dos produtos do trabalho -, continua a aparecer, para aqueles que se encontram no interior das relações de produção das mercadorias, como algo definitivo, mesmo depois daquela descoberta, do mesmo modo como a decomposição científica do ar em seus elementos deixou intacta a forma do ar como forma física corpórea. (MARX, 2013, p. 149).

Portanto, a superação do fetichismo da mercadoria é tarefa de um processo de transformação das relações sociais baseadas em um modo de produção, que tem como força motriz a produção mercantil. Nas palavras do autor (MARX, 2013, p. 154), "a figura do processo social de vida, isto é, do processo material de produção, só se livra de seu místico véu de névoa quando, como produto de homens livremente socializados, encontra-se sob seu controle consciente e planejado". Essa compreensão, de que o caráter alienado das relações sociais só é superado pela livre associação dos homens, Marx (2011) já delineava nos Grundrisse, ao tratar da alienação do trabalhador frente à introdução da maquinaria no processo produtivo.

Marx (2011) ressalta que o desenvolvimento da maquinaria é a expressão do avanço das forças produtivas a tal ponto que o trabalho se constitui como um "[...] mero elemento do processo de trabalho [...]" (ROSDOLSKY, 2001, p. 353). Por outro lado, esse mesmo desenvolvimento cria as condições para que o dispêndio da força de trabalho se reduza ao mínimo. No sentido contrário à sociedade baseada no valor de troca - em que as máquinas enfrentam o trabalhador como um poder hostil - em uma sociabilidade em que as forças produtivas sejam propriedade dos trabalhadores associados, e logo, o trabalho deixa de ser fonte de riqueza, surge a possibilidade de, agora, desenvolver livremente as individualidades e a redução do trabalho a um mínimo passa a corresponder "[...] à formação artística, científica etc. [...]" e não mais como forma de extração de mais-valor (MARX, 2011, p. 707).

Neste sentido, para Marx (2011, p. 109), o desenvolvimento do mercado mundial, da universalização do intercâmbio entre os homens, ainda que "[...] sob ponto de vista dado, não suprima a condição estranhada, dá lugar a relações e conexões que contêm em si a possibilidade de abolir o antigo ponto de vista". Aqui, Marx (2011), em uma das passagens mais inspiradoras dos Grundrisse, ressalta o aspecto positivo do desenvolvimento das formas de intercâmbio na superação do modo socialmente determinado, portanto, destaca:

É igualmente certo que os indivíduos não podem subordinar suas próprias conexões sociais antes de tê-las criado. Porém, é absurdo conceber tal conexão puramente coisificada como a conexão natural e espontânea, inseparável da natureza da individualidade (em oposição ao saber e ao querer reflexivos) e a ela imanente. A conexão é um produto dos indivíduos. É um produto histórico. Faz parte de uma determinada fase de seu desenvolvimento. A condição estranhada [Fremdartigkeit] e a autonomia com que ainda existe frente aos indivíduos demonstram somente que estes estão ainda no processo de criação das condições de sua vida social, em lugar de terem começado a vida social a partir dessas condições. É a conexão natural e espontânea de indivíduos em meio a relações de produção determinadas, estreitas. Os indivíduos universalmente desenvolvidos, cujas relações sociais, como relações próprias e comunitárias, estão igualmente submetidas ao seu próprio controle comunitário, não são um produto da natureza, mas da história. (MARX, 2011, p. 109-110, grifo do autor, grifo nosso).

É nessa perspectiva que Marx (2011) vislumbra a superação da forma como se estabelecem as relações entre os homens na sociedade baseada no valor de troca, na medida em tais relações representam somente um determinado estágio de desenvolvimento.

Ainda que em $O$ Capital (MARX, 2013) a terminologia alienação do trabalho não desempenhe o papel central como nos Manuscritos, Marx, ao apresentar a mercadoria, "[...] evidencia a independência do produto em relação aos produtores, [ali] a questão da alienação está posta, de saída, sem que Marx faça menção explícita a ela". (HALLAK, 2018, p. 59). Sánchez Vásquez (2007, p. 427), ressalta que no texto de 1867 a relação de alienação entre o produtor e os produtos do seu trabalho "é suposta e, inclusive, em algumas ocasiões exposta; Marx, com efeito, não deixa de mostrar às vezes como é afetado o trabalhador concreto, singular, como homem, isto é, em sua dignidade humana". Em ambos os textos, o que está em jogo para Marx é o fato de que as condições de objetivação - a relação entre sujeito e objeto - se desenvolvem a partir de relações sociais de produção determinadas, onde os homens "permanecem separados dos produtos em que se 
objetivam, e esses se tornam autônomos, escapam ao controle humano [...] e se apresentam com um poder próprio". (SÁNCHEZ VÁZQUEZ, 2007, p. 427).

Assim, entendemos que a descoberta realizada por Marx em 1844, da "raiz fundamental e primária do complexo fenomênico da alienação - com a propriedade privada, a divisão do trabalho e a produção mercantil" (PAULO NETTO, 2017, p. 170) é válida para todo o ciclo histórico de vigência do domínio do capital, porém, adquire formas inéditas no decorrer do seu desenvolvimento.

É com esta apreensão que se evidencia que "[...] a concepção de alienação não foi substituída pelo fetichismo das mercadorias, porque este representa somente um aspecto particular dela". (MUSTO, 2014, p. 88). Ou seja, alienação e fetichismo não são idênticos, uma vez que a alienação é uma categoria muito mais ampla, não se limitando ao caráter fetichista das mercadorias. Este "[...] implica a alienação, realiza uma alienação determinada e não opera compulsoriamente a evicção das formas alienadas mais arcaicas. O que ele instaura, entretanto, é uma forma nova e inédita que a alienação adquire na sociedade burguesa constituída [...]" (PAULO NETTO, 1981, p. 75, grifo do autor). Portanto, o caráter fetichista da mercadoria necessariamente implica a alienação, na medida em que "somente quando o produto do homem se aliena do seu produtor e aparece como um objeto independente dele é que pode surgir a situação mistificadora [do fetichismo]". (SCHAFF, 1967, p. 135 apud PAULO NETTO, 1981, p. 75).

\section{Considerações finais}

Partimos do pressuposto de que a teoria da alienação contida nos Manuscritos de 1844 constitui um ponto fundamental que expressa a aproximação de Marx com a economia política, enquanto as formulações sobre o fetichismo, nos Grundrisse e n'O Capital, são uma continuidade e uma superação do que Marx iniciou nos $\mathrm{Ma}$ nuscritos, na medida em que o fetichismo da mercadoria expressa a manifestação particular da alienação nos moldes da sociedade burguesa desenvolvida.

A concepção de alienação presente nos Manuscritos é resultado dos primeiros estudos marxianos acerca dos clássicos da economia política, portanto, ela contém limitações teóricas e objetivas. Teóricas, no sentido de que Marx ainda não se apropriara das categorias econômicas - dentre elas a categoria valor de troca que como vimos é fundamental para a descoberta do fetichismo; objetivas, no sentido de que as relações sociais burguesas não haviam desenvolvido todas as suas " “...] múltiplas determinações [...]" (MARX, 2011, p. 18), que permitiriam a Marx, posteriormente, apreender as formas de expressão da alienação insuspeitadas em 1844 (PAULO NETTO, 2017).

Vimos que, para Marx (2015), o trabalho é a atividade produtiva por meio da qual o homem transforma o mundo ao passo que transforma a si mesmo. É a "[...] própria vida produtiva [...]" é a "[...] vida que gera vida". (MARX, 2015, p. 312). Porém, a realização do trabalho nas condições da propriedade privada, da divisão do trabalho e da produção mercantil, aparece como desrealização do trabalhador, "[...] a objetivação como perda do objeto e servidão ao objeto, a apropriação como alienação, como exteriorização". (MARX, 2015 , p. 304, grifo do autor). Em outro momento, nos Grundrisse, Marx (2011), nesta mesma linha de raciocínio, ressalta que em relações sociais estreitas, essa atividade produtiva reveste-se do seu caráter alienado, onde do ponto de vista do trabalho "[...] aparece [...] como processo de alienação [...]" e do ponto de vista do capital, como "[...] apropriação do trabalho alheio [...]" (MARX, 2011, p. 930).

Nos Grundrisse e no Livro I d'O Capital, Marx (2011, 2013) introduz na problemática da alienação duas categorias econômicas fundamentais para o desenvolvimento da sua in-

Partimos do pressuposto de que a teoria da alienação contida nos Manuscritos de 1844 constitui um ponto fundamental que expressa a aproximação de Marx com a economia política, enquanto as formulações sobre 0 fetichismo, nos Grundrisse e n'O Capital, são uma continuidade e uma superação do que Marx iniciou nos Manuscritos, na medida em que o fetichismo da mercadoria expressa a manifestação particular da alienação nos moldes da sociedade burguesa desenvolvida. 
vestigação do MPC, quais sejam, o valor de uso e o valor de troca. O autor destaca que "como valor de uso, o trabalho só existe para o capital e é o valor de uso do próprio capital, i.e., a atividade mediadora pela qual ele se valoriza", consequentemente, o trabalho não existe para o trabalhador como valor de uso, ou seja, “[...] não existe para ele como força produtiva da riqueza [...]". O trabalhador leva a si mesmo como valor de uso para a troca com o capital "[...] que assim não se lhe confronta como capital, mas como dinheiro". (MARX, 2011, p. 240, grifo do autor). Nesse ato da troca - que se estabelece por meio do contrato de trabalho - o trabalho vivo é subsumido ao capital e, assim, é incorporado à essência do capital (DUSSEL, 2012).

Marx (2013) expõe aqui o movimento da mercadoria e suas metamorfoses ao longo do desenvolvimento das relações de troca, questiona o caráter místico que os produtos do trabalho humano assumem assim que se tornam mercadorias. Ao analisar esse movimento, nosso autor (MARX, 2013) descobre que como valor de uso - como um objeto que satisfaz as necessidades humanas - a mercadoria nada possui de misterioso. O segredo está no valor de troca que esconde as características sociais da mercadoria, ou seja, esconde a sua configuração como dispêndio de trabalho humano, assim, esconde aquilo que lhe determina valor. Para Marx (2013, p. 147), com a universalização das mercadorias, "[...] as relações entre os produtores, nas quais se efetivam aquelas determinações sociais de seu trabalho, assumem a forma de uma relação social entre os produtos do trabalho", este fenômeno, em que a relação entre o produto e o produtor aparece como uma relação entre coisas, Marx (2013) denomina de fetichismo da mercadoria o caráter místico que encobre as relações sociais de produção. Assim, podemos observar o caminho que levará Marx ao fetichismo da mercadoria como uma das expressões da alienação no modo de produção capitalista desenvolvido.

Marx (2011) demonstra como o valor de troca subverte a relação entre o homem e o seu produto, assim como a relação do homem com os outros homens a partir do momento em que a sua conexão social não é natural, livre, mas, sim, mediada pelo valor de troca. Podemos observar a permanência dos aspectos da alienação ressaltados anteriormente nos Manuscritos, mas nos Grundrisse e no Livro I d'O Capital aparecem com maior precisão teórica e relacionado com as múltiplas determinações que compõem a totalidade do MPC. Entretanto, é necessário considerar que as formulações presentes nos Grundrisse expressam um momento de investigação de Marx, momento em que "[...] tem de se apropriar da matéria em seus detalhes, analisar suas diferentes formas de desenvolvimento e rastrear seu nexo interno". (MARX, 2013, p. 90). Portanto, partilhamos da compreensão de que por meio dos Grundrisse "[...] foi possível reconstruir o percurso de elaboração dos escritos de juventude aos de $O$ Capital'. (MUSTO, 2014, p. 82). O que encontramos em $O$ Capital é a exposição do movimento real do objeto analisado, por isso, podemos encontrar no fetichismo da mercadoria a essência por traz da aparência do mundo das mercadorias, onde estas aparecem para os seus produtores como coisas, independentes do trabalho humano.

Para Marx, nos Manuscritos de 1844, se a alienação "procede por meios práticos, só meios igualmente práticos poderão superá-la [...]” (PAULO NETTO, 2015, p. 75), por essa razão, a superação da propriedade privada é a apropriação da vida humana, isto é, o regresso do homem à sua existência humana e social. $\mathrm{O}$ comunismo para Marx - neste primeiro momento da sua trajetória intelectual - é a supressão positiva da propriedade privada e, necessariamente, implica em outra forma de produzir a vida social, isto é, um novo modo de produção, na medida em que o modo de produção vigente não permite que o homem se realize como tal. Nos Grundrisse e em $O$ Capital, sem abandonar essa perspectiva, Marx amplia a sua compreensão de superação da alienação e conseguinte, das relações fetichizadas. A superação dos processos alienantes que se desenvolvem no bojo do MPC só é possível na livre associação dos trabalhadores por meio da retomada das condições materiais de produção, por meio de um movimento prático, isto é, por uma revolução que transforme radicalmente as relações sociais em que estão postas as condições para a alienação e, consequentemente, para o fetichismo.

\section{Referências}

DUSSEL, E. A produção teórica de Marx: um comentário aos Grundrisse. São Paulo: Expressão Popular, 2012.

HALLAK, M. Alienação do trabalho em Marx: dos Manuscritos de 1844 a O capital. Verinotio-Revista on-line de Filosofia e Ciências Humanas, Rio das Ostras, ano 13, v. 24, n. 1, p. 58-73, abr. 2018.

KONDER, L. Marxismo e alienação: contribuição para um estudo do conceito marxista de alienação. São Paulo: Expressão Popular, 2009.

MARX, K. O capital: crítica da economia política: livro I: o processo de produção do capital. São Paulo: Boitempo, 2013.

MARX, K. Grundrisse: manuscritos econômicos de 1857-1858: esboços da crítica da economia política. São Paulo: Boitempo; Rio de Janeiro: Editora UFRJ, 2011.

MARX, K. Cadernos de Paris \& manuscritos econômicos-filosóficos de 1844. São Paulo: Expressão Popular, 2015.

MÉSZÁROS, I. A teoria da alienação em Marx. São Paulo: Boitempo, 2016. 
MUSTO, M. Revisitando a concepção de alienação em Marx. In: DEL ROIO, M. (org.). Marx e a dialética da sociedade civil. Marília: Oficina Universitária; São Paulo: Cultura Acadêmica, 2014. p. 61-93.

PAULO NETTO, J. Capitalismo e reificação. São Paulo: Ciências Humanas, 1981.

PAUlO NETTO, J. Da recepção dos Manuscritos de 1844. In: BRAZ, M. (org.). José Paulo Netto: ensaios de um marxista sem repouso. São Paulo: Cortez, 2017. p. 166-174.

PAUlO NETTO, J. Marx em Paris. In: MARX, K. Cadernos de Paris \& manuscritos econômico-filosóficos de 1844. São Paulo: Expressão Popular, 2015. p. 9-178.

ROSDOLSKY, R. Gênese e estrutura de O capital de Karl Marx. Rio de Janeiro: EDUERJ: Contraponto, 2001.

SÁNCHEZ VÁZQUEZ, A. Filosofia da práxis. Buenos Aires: Consejo Latinoamericano de Ciencias Sociales; São Paulo: Expressão Popular, 2007.

\section{Notas}

1 As reflexões contidas neste artigo resultam de um dos capítulos da Dissertação de Mestrado intitulada Uma Aproximação às Categorias da Alienação, Fetichismo e Consciência em Marx, defendida no Programa de Pós-Graduação em Serviço Social da Universidade Federal de Juiz de Fora, de autoria de Jéssica Ribeiro Duboc sob orientação da Prof. ${ }^{a}$ Dr. ${ }^{a}$ Maria Lúcia Duriguetto.

2 Portanto, o trabalho é a atividade consciente livre que diferencia o homem do animal, tendo em vista que: "O animal é imediatamente um com a sua atividade vital. Não se diferencia dela, é ela. O homem faz a sua própria atividade vital objeto da sua vontade e da sua consciência. Tem atividade vital consciente. Não é uma determinidade com a qual ele se confunda imediatamente. A atividade vital consciente diferencia imediatamente o homem da atividade vital animal. Precisamente apenas por isto ele é um ser genérico. Ou ele só é um ser consciente, i.e., a sua própria vida é para ele objeto, precisamente porque ele é um ser genérico. Só por isso a sua atividade é atividade livre”. (MARX, 2015, p. 312).

3 É importante observar que aqui Marx desenvolve o duplo aspecto do trabalho na produção de mercadorias, qual seja, trabalho abstrato e trabalho concreto útil. Para o autor (MARX, 2013, p. 118-119), "todo trabalho é, por um lado, dispêndio de força humana de trabalho em sentido fisiológico, e graças a essa sua propriedade de trabalho humano igual ou abstrato ele gera o valor das mercadorias. Por outro lado, todo trabalhoé dispêndio de força humana de trabalho numa forma específica, determinada à realização de um fim, e, nessa qualidade de trabalho concreto eútil, ele produz valores de uso".

\section{Jéssica Ribeiro Duboc}

jessicadubocss@gmail.com

Mestrado em Serviço Social pelo Programa de Pós-Graduação em Serviço Social da Universidade Federal de Juiz de Fora (UFJF)

Doutoranda em Serviço Social pelo Programa de Pós-Graduação em Serviço Social da Escola de Serviço Social da Universidade Federal do Rio de Janeiro (UFRJ)

\section{UFRJ}

Escola de Serviço Social

Av. Pasteur, 250 - Urca

Rio de Janeiro - Rio de Janeiro - Brasil

CEP: $22.290-240$

\section{Maria Lúcia Duriguetto}

maluduriguetto@gmail.com

Doutorado em Serviço Social pelo Programa de Pós-Graduação em Serviço Social da Escola de Serviço Social da Universidade Federal do Rio de Janeiro (UFRJ)

Professora Associada da Faculdade de Serviço Social da Universidade Federal de Juiz de Fora (UFJF)

\section{UFJF}

Rua José Lourenço Kelmer, s/n - Campus Universitário - São Pedro

Juiz de Fora - Minas Gerais - Brasil

CEP: $36.036-900$ 


\section{Agência financiadora}

Jéssica Ribeiro Duboc: a pesquisa foi desenvolvida durante o mestrado, com a bolsa oferecida pela Universidade Federal de Juiz de Fora no período de 09/2017 a 03/2018, não possui número ou protocolo, não foi financiada por projeto específico.

Maria Lúcia Duriguetto: bolsista CNPq PQ2, número 303016/ 2015-9.

\section{Contribuições das autoras}

Ambas as autoras participaram da construção e redação do artigo que é fruto de uma pesquisa desenvolvida no mestrado em Serviço Social pela autora Jéssica Ribeiro Duboc sob orientação da autora Prof. ${ }^{\text {a }}$ Dr. ${ }^{\text {a }}$ Maria Lúcia Duriguetto.
Aprovação por Comitê de Ética e consentimento para participação

Não se aplica.

\section{Consentimento para publicação}

Não se aplica.

\section{Conflito de interesses}

Não há conflito de interesses. 